\title{
Broadband mm-Wave Microstrip Array Antenna with Improved Radiation Characteristics for Different 5G Applications
}

\author{
Mohsen Khalily, Member, IEEE, Rahim Tafazolli, Senior Member, IEEE, Pei Xiao, Senior Member, IEEE, and \\ Ahmed A. Kishk, Fellow, IEEE
}

\begin{abstract}
A Ka-band inset-fed microstrip patches linear antenna array is presented for the fifth generation (5G) applications in different countries. The bandwidth is enhanced by stacking parasitic patches on top of each inset-fed patch. The array employs 16 elements in an H-plane new configuration. The radiating patches and their feed lines are arranged in an alternating out-of-phase 180-degree rotating sequence to decrease the mutual coupling and improve the radiation pattern symmetry. A $(24.4 \%)$ measured bandwidth $(24.35$ to $31.13 \mathrm{GHz})$ is achieved with $-15 \mathrm{~dB}$ reflection coefficients and $20 \mathrm{~dB}$ mutual coupling between the elements. With uniform amplitude distribution, a maximum broadside gain of $19.88 \mathrm{dBi}$ is achieved. Scanning the main beam to $49.5^{\circ}$ from the broadside achieved $18.7 \mathrm{dBi}$ gain with -12.1 dB sidelobe level (SLL). These characteristics are in good agreement with the simulations, rendering the antenna to be a good candidate for $5 \mathrm{G}$ applications.
\end{abstract}

Index Terms-26 GHz, $28 \mathrm{GHz}$, millimeter wave (mm-Wave), fifth generation (5G), mobile communication, array antenna, parasitic antenna.

\section{INTRODUCTION}

D UE to the shortage of frequency spectrum below $6 \mathrm{GHz}$ bands and the need for higher data rate, higher frequencies, e.g., millimeter-wave (mm-Wave) frequency bands, have been suggested as candidates for future fifth generation (5G) smart-phone applications, as the considerably more substantial bandwidth could be exploited to increase the capacity and enable users to experience several-gigabits-per-second data rates [1]-[3]. However, one critical problem for $\mathrm{mm}$-Wave wireless is the increased link loss due to the reduced wavelength and atmospheric conditions [4], [5].

Commonly referred to as beamforming, a high gain narrow beam radiation pattern synthesized by an array consisting of multiple antenna elements with optimized spacing is a solution to combat the increased path loss at $\mathrm{mm}$-Wave frequencies. Also at mm-Wave frequencies, communication is mostly line of sight ( $\operatorname{LoS})$, communication links can thus be disrupted if the line of sight is not maintained. This can be solved by varying the phase shift associated with each antenna element, thereby steering the overall radiation pattern of the array [1] [5].

This work was supported in part by the 5GIC, University of Surrey, U.K. Mohsen Khalily, R. Tafazolli, and P. Xiao are with the Institute for Communication Systems, 5GIC, University of Surrey, Guildford, GU2 7XH, U.K. (email:m.khalily@surrey.ac.uk; r.tafazolli@surrey.ac.uk; p.xiao@surrey.ac.uk).

Ahmed A Kishk is with the Department of Electrical and Computer Engineering, Concordia University, Montreal, QC H3G 2W1, Canada (e-mail: kishk@encs.concordia.ca).
Although planar phased arrays have gone through intensive investigations, to date, limited research has been conducted on array antennas or phased arrays for mobile units [5], [6]. In [7], the authors present the motivation for new mm-Wave cellular systems, methodology, and hardware for measurements and offer a variety of measurement results showing that 28 and $38 \mathrm{GHz}$ frequencies can be used when employing steerable directional antennas at base stations and mobile devices. A new dense dielectric patch array antenna using electromagnetic band gap (EBG) ground structure and dielectric superstrate was recently proposed in [8] with an improved radiation characteristic, a high gain about $16.3 \mathrm{dBi}$ and bandwidth from $27 \mathrm{GHz}$ to beyond $32 \mathrm{GHz}$. In [5], a 2-GHz bandwidth around $28 \mathrm{GHz}$, an $11 \mathrm{dBi}$ gain and wide space coverage were achieved by using a thick multilayer coplanar waveguidebased array antenna. A new phased array antenna based on an open slot-PIFA integrated with the mobile phone chassis was designed in [3] with a bandwidth of $6 \mathrm{GHz}$ around $29 \mathrm{GHz}$ and a gain of about $13 \mathrm{dBi}$. In [9], notch antennas based on microstrip feeding and aperture coupled slot antennas were employed to design $1 \times 4$ arrays. Even though the antenna was compact, the bandwidth achieved was narrow. Finally, we recently proposed a new $28 \mathrm{GHz}$ series-fed phased array antenna in [10] with a reduced number of the phase controllers and $15.6 \mathrm{dBi}$ gain. In this work, a measured bandwidth of about $2 \mathrm{GHz}$ around $28 \mathrm{GHz}$ and a low beam scanning range of about $24^{\circ}$ were obtained.

To overcome the above-stated problems, a high gain array antenna system with broadband frequency performance, proper matching, stable radiation characteristics and high capability for beam scanning along with suitable sidelobe level (SLL) and the sharp radiating beam is achieved. Furthermore, the proposed antenna covers the $5 \mathrm{G}$ spectrum in different countries, such as $26 \mathrm{GHz}$ band in Europe [11] and the $28 \mathrm{GHz}$ band in the US [12].

In this paper, these goals are considered in the design of a new array antenna prototype from 25 to $30 \mathrm{GHz}$ for $5 \mathrm{G}$ spectrum supported in different countries and regions, especially Europe, USA and Asia. In the next section, the design of a single inset-fed patch antenna with an equal-size parasitic patch and its radiation and impedance characteristics are presented. In the following, a 16-element array antenna with a new configuration is proposed and designed to obtain the highest possible gain and bandwidth as well as good radiation performance. The two innovations of this design 
include 1- not-aligned antenna patches relative to each other to create symmetry in the final radiation fields, and 2- applying parasitic patches to the array antenna to increase the gain and bandwidth. Finally, the measurement results compared to the simulations as well as other works and conclusion are presented, respectively.

\section{Design of a Single Parasitic-Based InSET-Fed PATCh ANTENNA}

In this section, a new Inset-fed patch antenna using a parasitic patch is proposed and designed. The configuration of the single antenna is shown in Fig. 1. Two substrates, sub1 and sub2 with equal size of $6.2 \mathrm{~mm} \times 7 \mathrm{~mm}$ are employed to keep the radiation patch and the parasitic patch, respectively. In this design, a thin Roger 5880 substrate with thickness $=0.254$ $\mathrm{mm}$, dielectric constant $=2.2$ and very low dielectric loss is used for both Sub1 and Sub2. The size of the radiation patch and the parasitic patch are equal to each other $(3.44 \times 4.6$ $\mathrm{mm}^{2}$ ). Two gap sections, inside the excited patch, as two inset sections of the inset-fed patch antenna, are defined in optimal values of $0.05 \times 0.15 \mathrm{~mm}^{2}$. By carefully selecting these values, a proper input impedance matching can be obtained. The width of the input $50-\Omega$ microstrip feed line is about 0.74 $\mathrm{mm}$. To adjust the coupling between two patches (radiated and parasitic patches), the value of the effective dielectric constant to obtain the maximum gain, and broader bandwidth; the distance between two substrates, top surface and a bottom surface (shown by Sub1 and Sub2), illustrated by dis in Fig. 1 is studied. The $S_{11}$ and H-plane (x-z plane) gain graphs of the antenna for different values of dis are presented in Figs. 2(a) and (b), respectively. The related results for the antenna without the parasitic element are also presented in Fig. 2 for comparison.

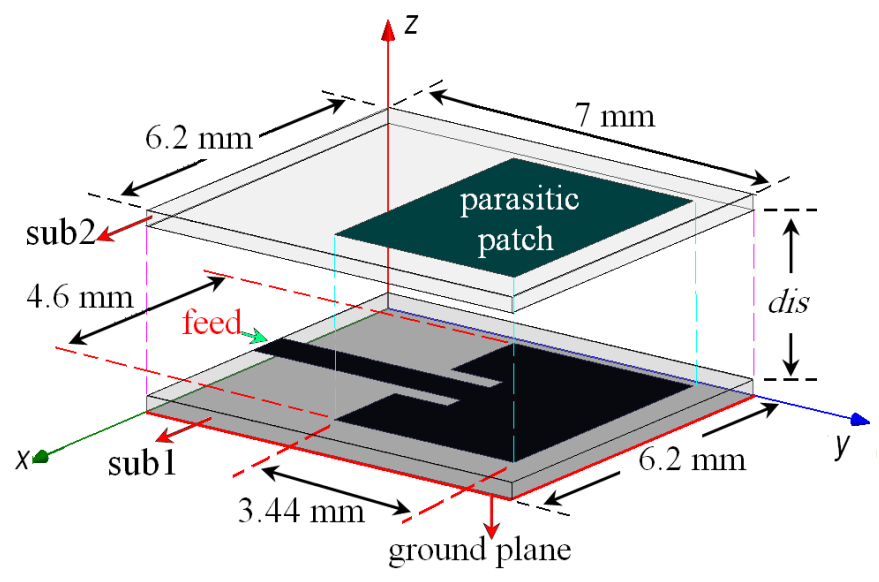

Fig. 1. The configuration of the proposed parasitic-patch-based inset-fed patch antenna.

Fig. 2(a) shows that in the initial state of the antenna design without the parasitic element, the impedance characteristic and the related matching are inferior. It is interesting that by adding the parasitic element with the same size as the radiation patch, the impedance bandwidth and matching are significantly improved in the 25 to $31 \mathrm{GHz}$ frequency range. In addition, as shown in Fig. 2(b), the parasitic element causes
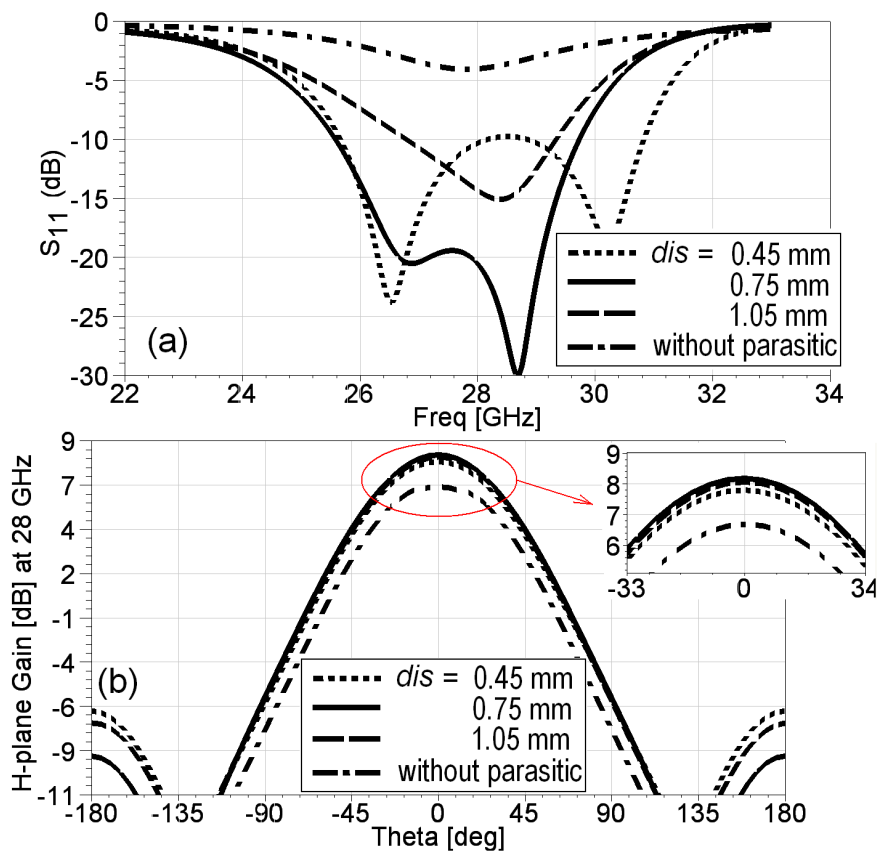

Fig. 2. (a) $S_{11}$, (b) H-plane gain graphs of the single parasitic Inset-fed patch antenna for different values of dis.

a significant increase (about $1.6 \mathrm{~dB}$ ) in the gain at $28 \mathrm{GHz}$ as well as improves the antenna efficiency and decreases the SLL. According to these results, the best value for dis is 0.75 $\mathrm{mm}$. With this choice, the 10-dB impedance bandwidth is from 25.55 to $29.75 \mathrm{GHz}(15.18 \%$ ), and the broadside gain is about $8.2 \mathrm{dBi}$. Moreover, an excellent impedance matching can be seen within the band, which are very desirable characteristics for the $5 \mathrm{G}$ applications.

\section{Design of a New Array Antenna}

\section{A. Study of two different configurations of a two array antenna}

In this part, two different configurations for a two element array antenna are studied. Two configurations consist of two parallel antennas (Case 1) and two non-aligned antennas (Case 2). These two structures are depicted in Fig. 3 (a). In both situations, the distance between the two antennas is $6.2 \mathrm{~mm}$ $\left(0.56 \lambda_{0} @ 28 \mathrm{GHz}\right)$. With this choice, the maximum gain in the broadside thet $a=0^{\circ}\left(\theta=0^{\circ}\right)$, the best SLL, and the desired $3 \mathrm{~dB}$ beamwidth can be obtained.

When two antennas are aligned in Case 1, both of them must be excited by input phase equal to zero (or similar phase). In Case 2, the input phase of the antennas must have a $180^{\circ}$ difference. These configurations have the lowest effect on the H-plane pattern, $S_{11}$ graph and the impedance matching. But on the other hand, there is a remarkable change in the Eplane pattern, especially on the symmetry of the pattern, the beam position, the broadside gain, and SLL. The result of this analysis is presented in Fig. 3 (a). It is clear that in the conventional arrangement of the linear array elements (Case 1) the pattern is not symmetric with respect to the $\theta=0^{\circ}$ angle. A $5^{\circ}$ change can be observed. Hence, this situation is not desirable for space scanning. In addition, the value of the SLL is equal to $-10.6 \mathrm{~dB}$ in case 1 . In the proposed 

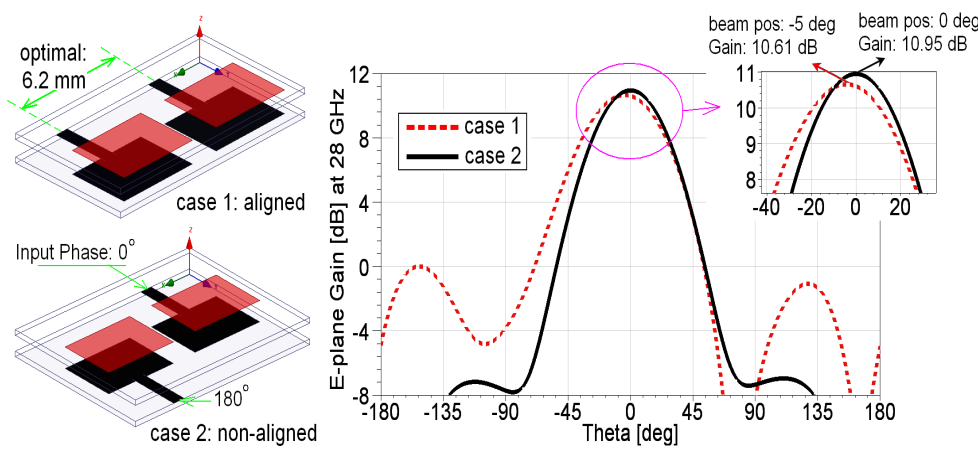

(a)

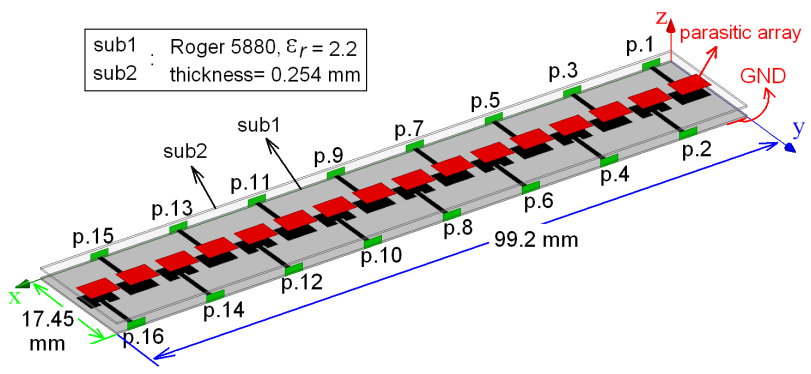

(b)

Fig. 3. (a) Two different configurations (aligned and non-aligned) for a $2 \times 1$ array antenna, and their E-plane (y-z plane) gain graphs at $28 \mathrm{GHz}$, (b) The configuration of the proposed 16-element parasitic-patch-based Inset-fed patch array antenna.

case (Case 2), the pattern is symmetric, as you can see from Fig. 3 (a). Moreover, the values of the broadside gain and SLL have been improved by about $0.34 \mathrm{~dB}$ and $7.5 \mathrm{~dB}$, respectively. As a result, designing a large array antenna using the proposed configuration (Case 2) can produce desirable radiation performance for practical deployment.

\section{B. Design of a new 16-element array antenna}

In this part, the main goal is to design an array antenna using the proposed two array configuration and as large as a typical mobile phone. Hence, the maximum array length can be around $100 \mathrm{~mm}$. In this study, two different situations for the main beam position are considered in the H-plane pattern: 1) the beam position at $\theta=0^{\circ}$ and 2) the scanning direction at $\theta$ $= \pm 45^{\circ}$. It should be noted that our reference to determine and accept the maximum possible scanning is SLL of $-10 \mathrm{~dB}$. The structure of the proposed 16-element linear array antenna is shown in Fig. 3(b). The total size of the design is $17.45 \times 99.2$ $\mathrm{mm}^{2}$. In this design, 16 parasitic elements are employed at the top surface of Sub2 with a size of $3.44 \times 4.6 \mathrm{~mm}^{2}$ equal to the excited inset-fed patches. The other properties of the design are defined in Fig. 3(b). In order to simulate the antenna array, 16 feed ports (P1 to P16) are excited by input signals with equal amplitudes, but different phases to scan the main beam in the $\mathrm{X}-\mathrm{Z}$ plane. It is noted that the distance between the array elements (for example: between P1 and P2) is about $6.2 \mathrm{~mm}$ $\left(0.56 \lambda_{0} @ 28 \mathrm{GHz}\right)$. Moreover, we know that to scan the main beam from $\theta=0^{\circ}$ (z-axis) to $\theta=90^{\circ}$ (x-axis) and place it at a specific angle $\theta_{0}\left(0^{\circ}<\theta<90^{\circ}\right)$, a definite phase difference $(=d p h i)$, equal to $\beta d \sin \left(\theta_{0}\right)$ is needed between each pair of array elements, consecutively. Here, $\beta$ is equal to $2 \pi / \lambda_{0}$ and $d=0.56 \lambda_{0}$. Hence, the parameter $d p h i$ is equal to $1.12 \pi \times$ $\sin \left(\theta_{0}\right)$. On the other hand, by considering the excitation phase mechanism of the antennas, proposed in Fig. 3(a) (Case2) and the crucial phase difference $(=d p h i)$ required between them to direct the main beam, the input excitation phase of each feed port $(\measuredangle p . i, i=1,2, \ldots, 16)$ is defined by the following equation:

$$
\left\{\begin{array}{rlrl}
\measuredangle p . n & =(n-1) \times d p h i & & i=1,3, \ldots, 15 \\
\measuredangle p . n & =180^{\circ}+(n-1) \times d p h i & i & =2,4, \ldots, 16
\end{array}\right.
$$

In this study, by considering the reference SLL $=-10 \mathrm{~dB}$ and our parametric simulations, the parameter $\theta_{0}$ is selected to be about $50^{\circ}$. Therefore, the value of $d p h i$ will be equal to $154.5^{\circ}$. As mentioned above, two different situations for the main beam directions, $\theta_{0}=0^{\circ}$ and $\pm 50^{\circ}$ are selected to be studied. All simulations are performed by finite-elementmethod (FEM)-based Ansoft HFSS software. For the first position of the main beam $\left(\theta=0^{\circ}, d p h i=0^{\circ}\right)$, the simulated $\mathrm{S}$ parameters, H-plane ( $\mathrm{x}-\mathrm{z}$ plane) and E-plane (y-z plane) pattern gains of the proposed array antenna at $28 \mathrm{GHz}$ are shown in Fig. 4, respectively. From Fig. 4(a), it is seen that the $10-\mathrm{dB}$ bandwidth is from 25.3 to $30 \mathrm{GHz}(17 \%)$. The isolation between nearest two ports (P1 and P2) is more than $19 \mathrm{~dB}$ within the band mentioned above. As desired, Fig. 4(b) shows the main beam is located at $\theta_{0}=0^{\circ}$. In addition, the difference between co- and cross-polar is more than $50 \mathrm{~dB}$ in the broadside and the front to back ratio is better than $25 \mathrm{~dB}$. A wide beam in broadside for E-plane pattern can be seen in Fig. 4(c). Here, the difference between co- and cross-polar is more than $50 \mathrm{~dB}$. Fig. 5 presents the graphs of the same parameters mentioned above, for the main beam at $\left(\theta_{0}= \pm 50^{\circ}, d p h i=\right.$ $154.5^{\circ}$ ) of the proposed array at $28 \mathrm{GHz}$. It is clearly seen from Fig. 5(a) that the impedance bandwidths and isolation are similar to the previous results of the broadside direction. The main beam scanned to $-49^{\circ}$ is shown in Fig. 5(b). Here, the difference between co- and cross-polar is better than $53 \mathrm{~dB}$ around $\theta=-49^{\circ}$. Again, a wide beam and a high difference between co- and cross-polar (more than $23 \mathrm{~dB}$ ) in E-plane pattern are seen in Fig. 5(c).

In the final step of the simulation, for further investigation of array antenna performance within the bandwidth, the $\mathrm{H}$ plane pattern of the array at $26 \mathrm{GHz}$ is also presented in Fig. 6. As can be seen in the figure, both cases with different beam directions are shown for comparison. The radiation properties are summarized in Table I. It is interesting to note that the main beam of the scanned case is located at $-54^{\circ}$ with high gain and SLL. The $-54^{\circ}$ scanned has a scanning loss of 0.78 $\mathrm{dB}$. The $3 \mathrm{~dB}$ beamwidths are less than $9^{\circ}$ in both cases. These feature characteristics for a $5 \mathrm{G}$ spectrum are supported by different countries. The other important parameters of the radiation patterns of the proposed array antenna in the two cases are summarized in Table I for 26 and $28 \mathrm{GHz}$. As 

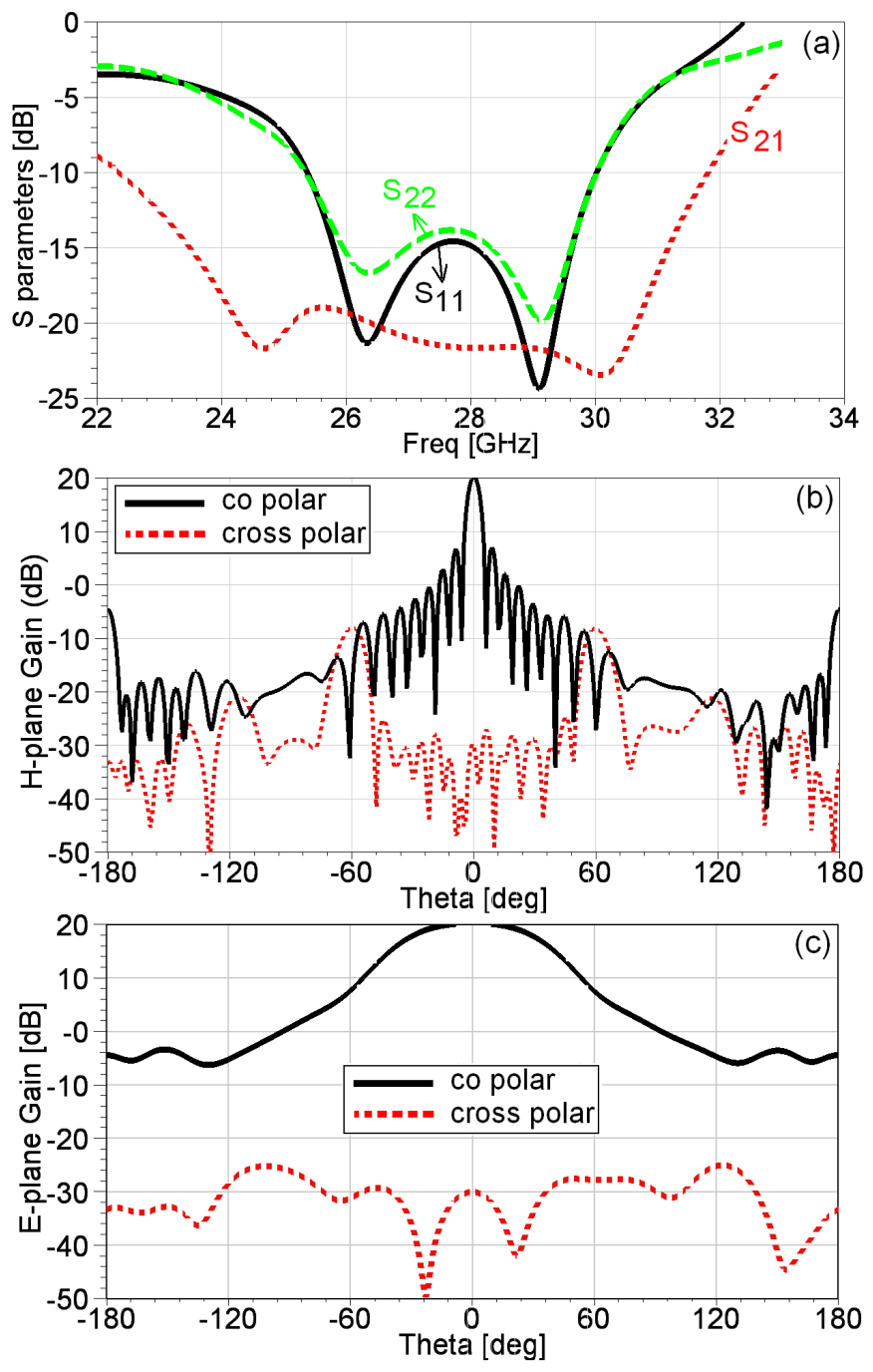

Fig. 4. Simulated (a) S parameters, (b) H-plane and (c) E-plane radiation gains of the proposed array antenna $\left(\theta_{0}=0^{\circ}, d p h i=0^{\circ}\right)$ at $28 \mathrm{GHz}$.

shown in Table I, a high gain in both situations is achieved. Hence, the scan loss is about $1.4 \mathrm{~dB}$ and $0.78 \mathrm{~dB}$ at 28 and $26 \mathrm{GHz}$, respectively. The values of the SLL in each case are lower than $-11.5 \mathrm{~dB}$, which makes the antenna very efficient to focus in one direction for both frequency bands. This improves the quality of the $5 \mathrm{G}$ communication link. In addition, the proposed array antenna offers a narrow beamwidth in all scanning direction less than $-54^{\circ}$, which is an advantage for point-to-point communications. Finally, these promising features make the proposed array antenna a viable solution in different $5 \mathrm{G}$ spectrum bands.

\section{Measurement Results and Discussion}

In order to validate the simulated results, a prototype of the proposed array antenna is fabricated and measured. The photos of the prototype are shown in Fig. 8 (a). Similar to the design shown in Fig. 3(b), two Roger 5880 substrates, Sub1 and Sub2 with a thickness of $0.254 \mathrm{~mm}$ are employed with a $0.75 \mathrm{~mm}$ spacing (air gap) from each other. Rohacell foam is used as air gap with the dielectric constant of 1.046
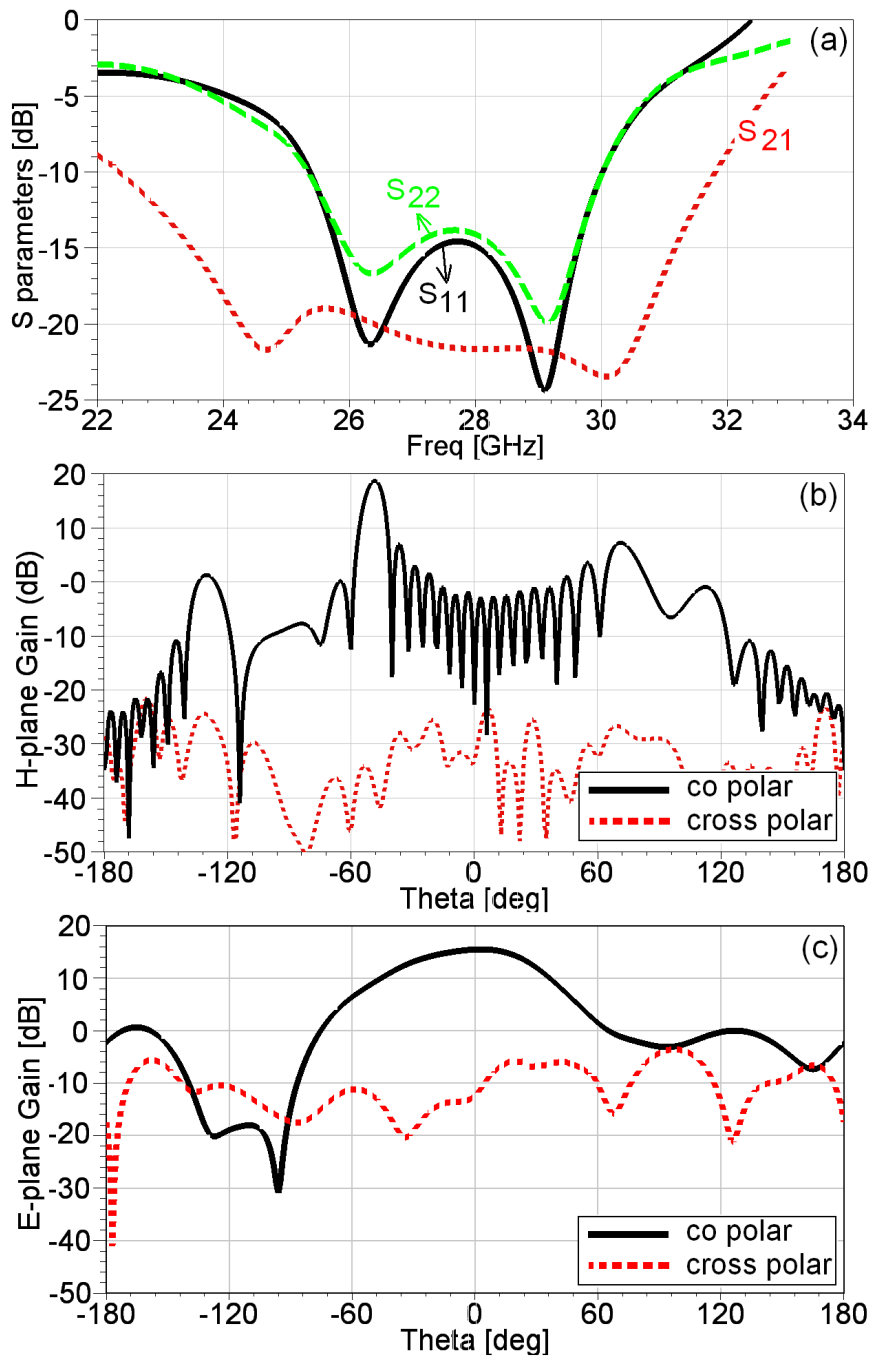

Fig. 5. Simulated (a) S parameters, (b) H-plane and (c) E-plane radiation gains of the proposed array antenna $\left(\theta_{0}= \pm 50^{\circ}, d p h i=154.5^{\circ}\right)$ at $28 \mathrm{GHz}$.

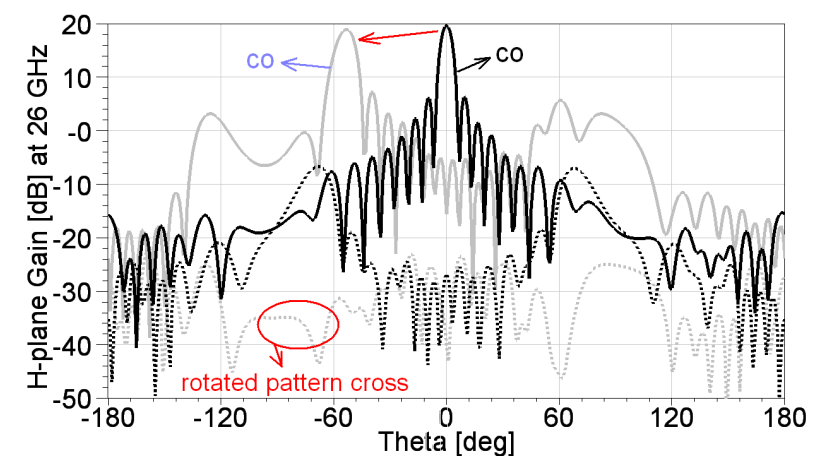

Fig. 6. Simulated H-plane radiation gains of the proposed array at $26 \mathrm{GHz}$ for two beam positions $\left(d p h i=0\right.$ and $\left.154.5^{\circ}\right)$.

and loss tangent of 0.0106 at $28 \mathrm{GHz}$ which is very close to the permittivity of air. Two different feeding network for boresight and scan cases are designed and fabricated as shown in Fig. 8(b) \& (c) and the vector network analyzer (VNA) is used to measure the $S_{11}$ with and without feeding network for the boresight and maximum scan angle. As it was mentioned 
TABLE I

THE PROPERTIES OF THE H-PLANE RADIATION PATTERNS OF THE PROPOSED ARRAY ANTENNA AT $26 \& 28 \mathrm{GHZ}$

\begin{tabular}{l|c|c|c|c|c|c|c|c}
\hline \hline Parameters & \multicolumn{2}{|c|}{ Beam position } & \multicolumn{2}{|c|}{ Max Gain } & \multicolumn{2}{c|}{ 3dB-beamwidth } & \multicolumn{2}{c}{ SLL } \\
\hline Frequency & $26 \mathrm{GHz}$ & $28 \mathrm{GHz}$ & $26 \mathrm{GHz}$ & $28 \mathrm{GHz}$ & $26 \mathrm{GHz}$ & $\mathrm{GHz}$ & $26 \mathrm{GHz}$ & $28 \mathrm{GHz}$ \\
\hline Boresight (Simulation) & $0^{\circ}$ & $0^{\circ}$ & $19.7 \mathrm{~dB}$ & $20.15 \mathrm{~dB}$ & $5.8^{\circ}\left(-2.9^{\circ} \sim+2.9^{\circ}\right)$ & $5.2^{\circ}\left(-2.6^{\circ} \sim+2.6^{\circ}\right)$ & $-13.2 \mathrm{~dB}$ & $-13.4 \mathrm{~dB}$ \\
\hline Maximum scan (Simulation) & $-54.5^{\circ}$ & $-49^{\circ}$ & $18.92 \mathrm{~dB}$ & $18.75 \mathrm{~dB}$ & $9^{\circ}\left(-50^{\circ} \sim-59^{\circ}\right)$ & $8^{\circ}\left(-45^{\circ} \sim-53^{\circ}\right)$ & $-11.5 \mathrm{~dB}$ & $-11.8 \mathrm{~dB}$ \\
\hline Boresight (Measurement) & $0^{\circ}$ & $0^{\circ}$ & $19.54 \mathrm{~dB}$ & $19.88 \mathrm{~dB}$ & $5.6^{\circ}\left(-2.8^{\circ} \sim+2.8^{\circ}\right)$ & $5^{\circ}\left(-2.5^{\circ} \sim+2.5^{\circ}\right)$ & $-13.4 \mathrm{~dB}$ & $-13.5 \mathrm{~dB}$ \\
\hline Maximum scan (Measurement) & $-54^{\circ}$ & $-49.5^{\circ}$ & $18.78 \mathrm{~dB}$ & $18.7 \mathrm{~dB}$ & $9.4^{\circ}\left(-49.3^{\circ} \sim-58.7^{\circ}\right)$ & $9^{\circ}\left(-45^{\circ} \sim-54^{\circ}\right)$ & $-11.75 \mathrm{~dB}$ & $-12.1 \mathrm{~dB}$ \\
\hline \hline
\end{tabular}

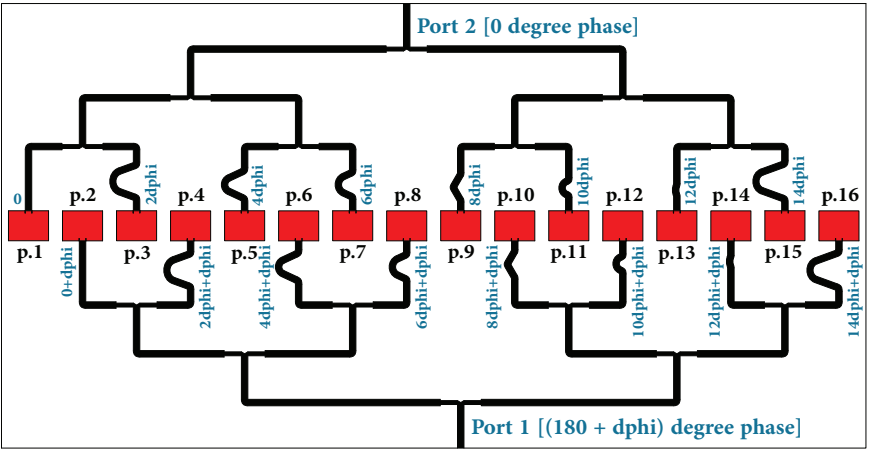

Fig. 7. Feeding Network configuration for the maximum scan $\left(d p h i=154^{\circ}\right)$ at $28 \mathrm{GHz}$.

in Section III, there is a phase difference of $180^{\circ}$ between the oppositely directed patches. On the other hand, even port numbers $(\measuredangle p . i, i=2,4, \ldots, 16)$ must be fed with $180^{\circ}$ phase to have the total phase of $360^{\circ}$ for boresight radiation. Here, for boresight case, one cooperative feeding network shown in Fig. 8(c) is designed and fabricated while $180^{\circ}$ phase difference has been applied by means of R\&S®ZVA67 in Port 1. As a result, all the elements of the array have the same phase, which results in a boresight radiation pattern. Also, for steering case of the proposed antenna where the progressive phase shift is needed at all the elements of the array, another feeding network is designed. It should be noted that one of the advantages of the proposed antenna array is to have more space between elements due to face to face excitation. The proposed configuration enables us to add more components such as phase shifters in the area between two neighbour patches compared to the conventional linear array antennas. Here, delay lines have been introduced at the input of all the radiating elements to provide the necessary progressive phase shift. A cooperative feeding network with delay lines is designed with $2 \times d p h i$ phase difference between two elements fed by the same power divider while R\&S®ZVA67 provides a $180^{\circ}+d p h i$ phase shift at Port 1 to ensure a progressive phase shift at all the elements. For steered beam case, delay lines are calculated to achieve a maximum scanning angle. Here, $d p h i$ $=154^{\circ}$, and phase difference of each branch is $2 \times 154^{\circ}$. As a result, P1 shown in Fig. 7 has $180^{\circ}+154^{\circ}$ phase, while P2 has $0^{\circ}$.

In the measurement setup of the different radiation patterns, the far-field radiation conditions are used to determine the positions of the prototype (as a receiver) and a standard Horn antenna (as a transmitter) as well as the distance between them. A 4-port R\&S@ZVA67 is used for the radiation pattern measurement after calibration while horn antenna is transmitting a signal generated from the R\&S®SMW200A signal generator. The measured $S_{11}$ with and without feeding network, H-plane and E-plane patterns at $28 \mathrm{GHz}$ for the boresight and scanned beam cases are shown in Figs. 9 and 10, respectively. Moreover, the graphs simulated above are presented in these figures for comparison. A good agreement between the simulated and measured for each case is observed. Although, the measured E-plane patterns in the scanned beam case (see Fig. 9(c) and Fig. 10(c)), are more symmetric compared to the simulated ones. The 10-dB $S_{11}$ bandwidth is also measured with feeding network, and it is from 24.35 to $31.13 \mathrm{GHz}(24.4 \%)$. It is observed for both cases that the impedance bandwidth of the antenna measured with feeding networks are slightly increased. Also, the impedance matching in the scanning case is decreased due to delay lines applied to the feeding network. Table I shows the properties of the measured H-plane radiation graphs in both cases. The loss for scanning from 0 to $-49.5^{\circ}$ is about $1.18 \mathrm{~dB}$. Similar to the simulated results, narrow beamwidths and suitable SLL levels are obtained with an acceptable difference compared to the simulations. In addition, the simulated and measured radiation efficiency values are better than $86 \%$.

In comparison with the other works, designed for $5 \mathrm{G}$ spectrum, our proposed array antenna has good features, suitable for $5 \mathrm{G}$ conditions. The properties of the comparisons are summarized in Table II for different parameters. In [3], an antenna with a $6 \mathrm{GHz}$ bandwidth $(26 \sim 32 \mathrm{GHz}), 13 \mathrm{dBi}$ gain, radiation efficiency of $75 \%$ and high scan loss was presented. The complex antenna proposed in [5] offers a low space covering about $70^{\circ}$ with $-10 \mathrm{~dB}$ SLL in the H-plane radiation pattern. In addition, the antenna has a low gain of $11 \mathrm{~dB}$ with relatively wider beamwidth about $20^{\circ}$. It's impedance bandwidth is about $2.6 \mathrm{GHz}$ around $28.8 \mathrm{GHz}$. Finally, in [8], the proposed array antenna with a complex structure has a wide bandwidth of about $5 \mathrm{GHz}$ around $29.5 \mathrm{GHz}$, SLL of $11.6 \mathrm{~dB}$ and a narrow beamwidth of $11^{\circ}$. However, it's realized gain and radiation efficiency are about $16.3 \mathrm{dBi}$ and $71.8 \%$, respectively.

\section{CONClusion}

By considering the worldwide need for cellular spectrum, and the relatively limited amount of research done on $\mathrm{mm}$ Wave mobile communications, we have designed a new phased array antenna prototype operating from 24 to $31 \mathrm{GHz}$. This band can be used for different $5 \mathrm{G}$ applications on different countries and regions, especially Europe, USA, and Asia. The array antenna has a powerful capability in steering the main 


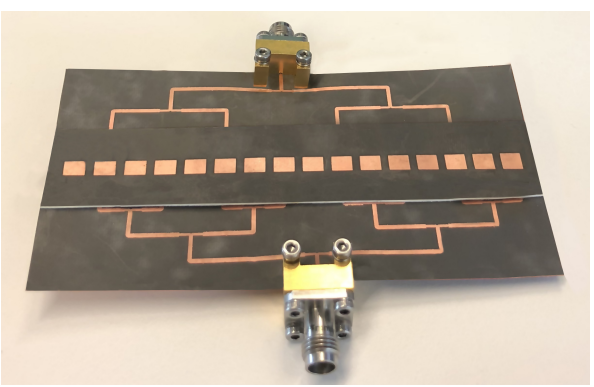

(a)

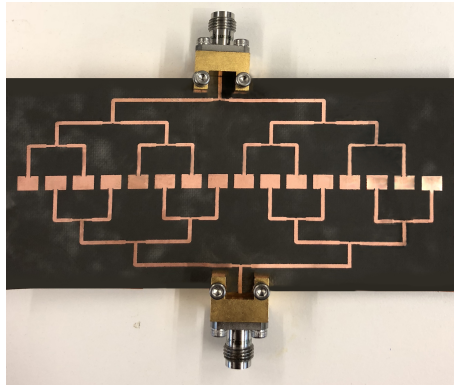

(b)

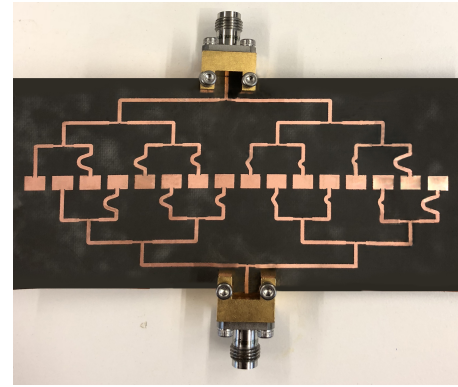

(c)

Fig. 8. Photos of the prototypes. (a) Excited elements covered with the parasitic elements, (b) Feeding network for boresight pattern,(c) Feeding network for the maximum scan $\left(d p h i=154^{\circ}\right)$ at $28 \mathrm{GHz}$.
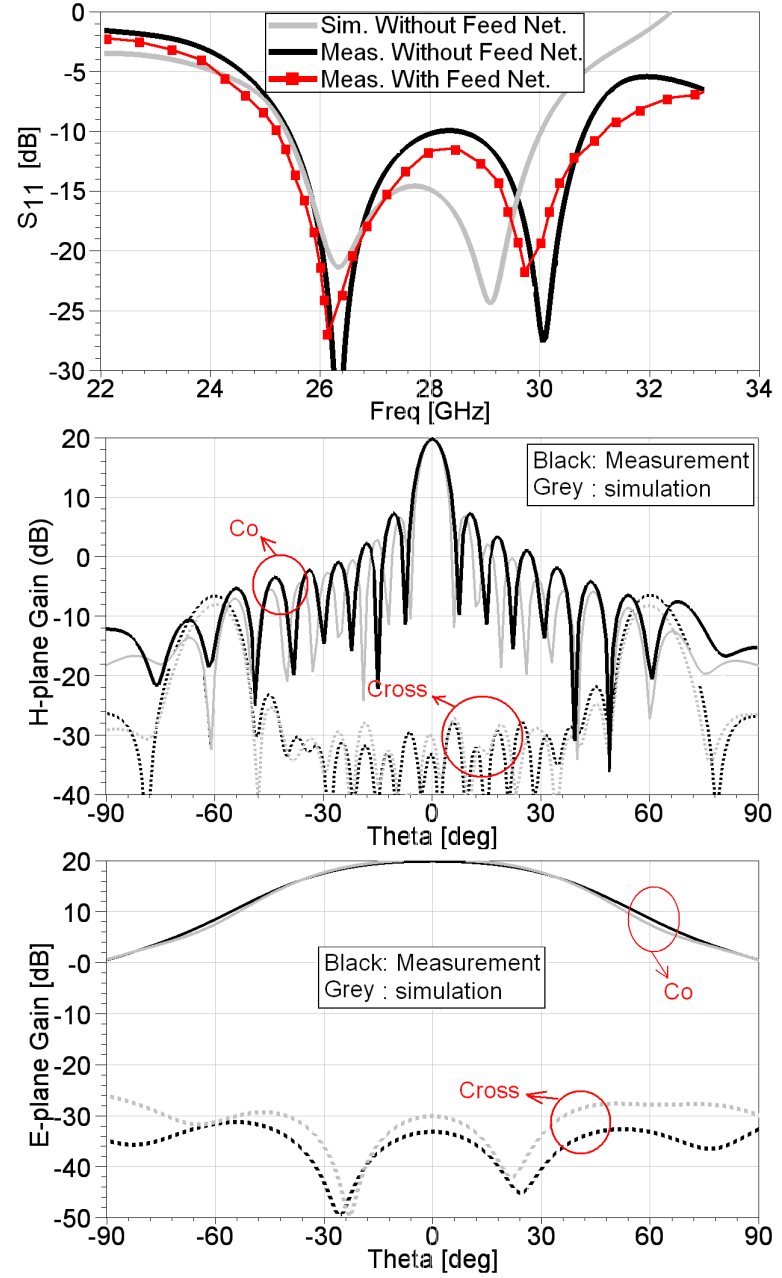

Fig. 9. (a) Simulated and measured $S_{11}$ with and without feeding network, (b) H-plane, and (c) E-plane radiation gains of the fabricated array antenna $\left(\right.$ dphi $\left.=0^{\circ}\right)$ at $28 \mathrm{GHz}$.

beam in the H-plane at both $26 \mathrm{GHz}$ and $28 \mathrm{GHz}$ with two innovating configurations. Stacking the excited patches with parasitic elements on the top and alternating the consecutive patches in the opposite direction to each other without of phasing, the total gain, bandwidth and the E-plane radiation pattern symmetric has been improved, considerably. The proposed array has been fabricated and tested with two different
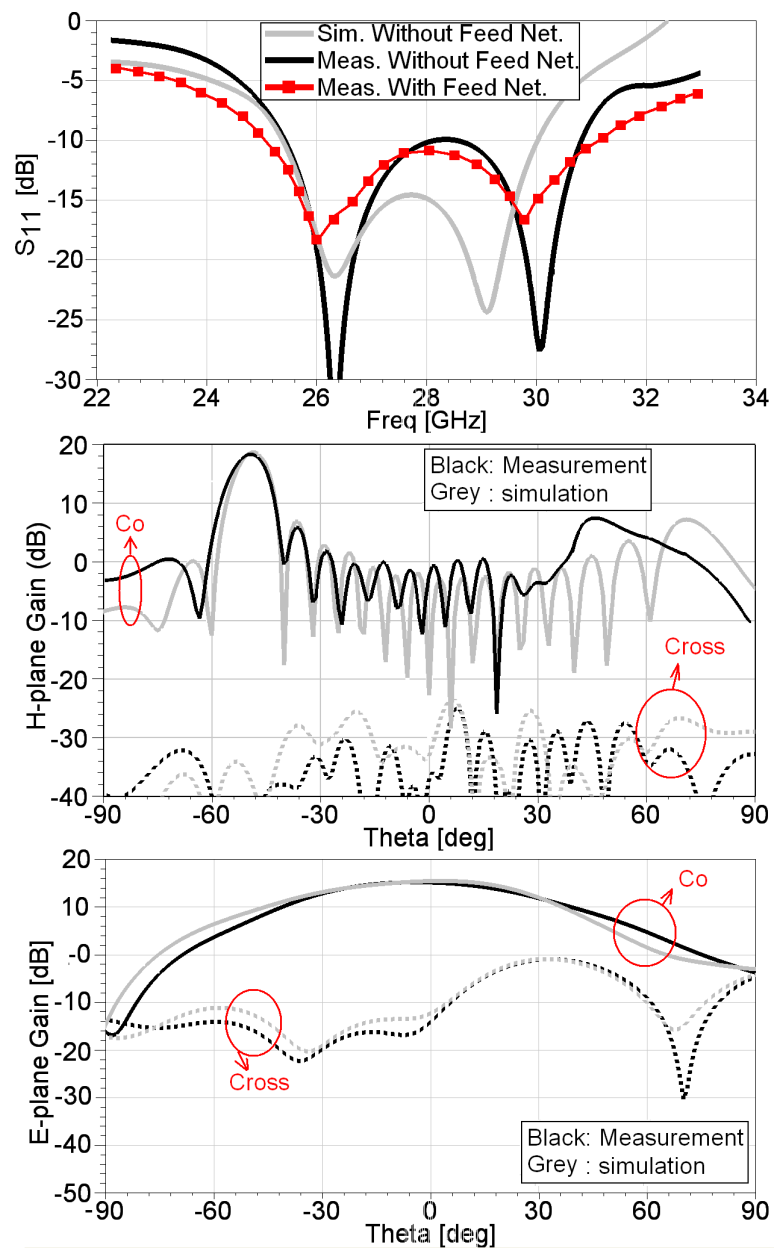

Fig. 10. (a) Simulated and measured $S_{11}$ with and without feeding network, (b) H-plane, and (c) E-plane radiation gains of the fabricated array antenna $\left(\right.$ dphi $\left.=154^{\circ}\right)$ at $28 \mathrm{GHz}$.

feeding network to point the main beam to the boresight and maximum scan direction. The measured results have shown high gains, low scan losses, and narrow beamwidths for both beam scanning direction. Moreover, high space covering of more than $100^{\circ}$ in H-plane with SLL less than $-12 \mathrm{~dB}$ has been achieved. Therefore, the proposed array antenna could be a good candidate for the future $5 \mathrm{G}$ applications with beam scanning capability in comparison with other designs. 
TABLE II

COMPARISON WITH OTHER REPORTED MILLIMETRE WAVE ARRAY ANTENNA FOR 5G APPLICATIONS

\begin{tabular}{cccccccc}
\hline \hline Works & Impedance,Bandwidth & Gain & Radiation Efficiency & SLL & Scan Range & 3-dB Beamwidth & Design Complexity \\
\hline$[3]$ & $6 \mathrm{GHz}$ & $13 \mathrm{dBi}$ & $75 \%$ & - & - & - & Moderate \\
{$[5]$} & $2.6 \mathrm{GHz}$ & $11 \mathrm{dBi}$ & - & $-10 \mathrm{~dB}$ & $70^{\circ}$ & $20^{\circ}$ & High \\
{$[8]$} & $5 \mathrm{GHz}$ & $16.3 \mathrm{dBi}$ & $71.8 \%$ & $-11.6 \mathrm{~dB}$ & - & $11^{\circ}$ & $5^{\circ}$ \\
This Work & $5.37 \mathrm{GHz}$ & $19.88 \mathrm{dBi}$ & $86 \%$ & $-13.4 \mathrm{~dB}$ & $108^{\circ}$ & $5^{\circ}$ & Low \\
\hline
\end{tabular}

\section{REFERENCES}

[1] J. G. Andrews, S. Buzzi, W. Choi, S. V. Hanly, A. Lozano, A. C. K. Soong, and J. C. Zhang, "What will 5G be?" IEEE Journal on Selected Areas in Communications, vol. 32, no. 6, pp. 1065-1082, June 2014.

[2] J. Qiao, X. S. Shen, J. W. Mark, Q. Shen, Y. He, and L. Lei, "Enabling device-to-device communications in millimeter-wave $5 \mathrm{G}$ cellular networks," IEEE Communications Magazine, vol. 53, no. 1, pp. 209-215, January 2015.

[3] M. Stanley, Y. Huang, T. Loh, Q. Xu, H. Wang, and H. Zhou, "A high gain steerable millimeter-wave antenna array for $5 \mathrm{G}$ smartphone applications," pp. 1311-1314, March 2017.

[4] W. Hong, K. H. Baek, Y. Lee, Y. Kim, and S. T. Ko, "Study and prototyping of practically large-scale mmwave antenna systems for $5 \mathrm{G}$ cellular devices," IEEE Communications Magazine, vol. 52, no. 9, pp. 63-69, September 2014.

[5] H. Zhou, "Phased array for millimeter-wave mobile handset," pp. 933934, July 2014.

[6] H. Zhou and F. Aryanfar, "Millimeter-wave open ended siw antenna with wide beam coverage," pp. 658-659, July 2013.

[7] T. S. Rappaport, S. Sun, R. Mayzus, H. Zhao, Y. Azar, K. Wang, G. N. Wong, J. K. Schulz, M. Samimi, and F. Gutierrez, "Millimeter wave mobile communications for 5G cellular: It will work!" IEEE Access, vol. 1, pp. 335-349, 2013.

[8] O. M. Haraz, A. Elboushi, S. A. Alshebeili, and A. R. Sebak, "Dense dielectric patch array antenna with improved radiation characteristics using ebg ground structure and dielectric superstrate for future 5G cellular networks," IEEE Access, vol. 2, pp. 909-913, 2014.

[9] J. Helander, K. Zhao, Z. Ying, and D. Sjberg, "Performance analysis of millimeter-wave phased array antennas in cellular handsets," IEEE Antennas and Wireless Propagation Letters, vol. 15, pp. 504-507, 2016.

[10] M. Khalily, R. Tafazolli, T. A. Rahman, and M. R. Kamarudin, "Design of phased arrays of series-fed patch antennas with reduced number of the controllers for $28 \mathrm{GHz} \mathrm{mm}$-wave applications," IEEE Antennas and Wireless Propagation Letters, vol. 15, pp. 1305-1308, 2016.

[11] Ofcom, "Ofcom notes: Update on 5G spectrum in the UK," 8 February 2017. [Online]. Available: https://www.ofcom.org.uk/data/assets/pdf_ file/0021/97023/5G-update-08022017.pdf

[12] "FCC takes steps to facilitate mobile broadband and next generation wireless technologies in spectrum above 24 GHz," Federal Communications Commission, Jul 2016. [Online]. Available: https://www.fcc.gov/document/ FCC-adopts-rules-facilitate-next-generation-wireless-technologies

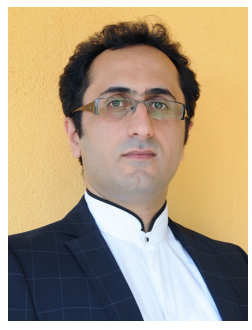

Mohsen Khalily (M'13) joined Institute for Communication Systems (ICS), home of 5G Innovation Center (5GIC) at University of Surrey, U.K. as a research fellow on antenna and propagation since December 2015. Before joining 5GIC, he worked with Wireless Communication Center (WCC), Universiti Teknologi Malaysia (UTM) as a Senior Lecturer and Postdoc Research Fellow from December 2012 to December 2015. Dr Khalily has published almost 70 academic papers in international peer-reviewed journals and conference proceedings. His research interests include: dielectric resonator antennas, MIMO antennas, phased array antennas, analog beamforming network, millimeter-wave antennas for $5 \mathrm{G}$ and mmWave propagation.

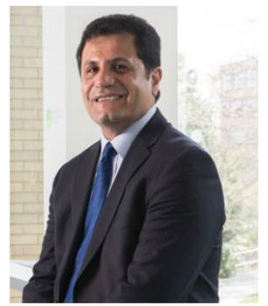

Rahim Tafazolli (SM'09) has been the Professor of Mobile and Satellite Communications at the University of Surrey since April 2000, Director of Institute of Communication Systems (ICS, formerly known as CCSR) since January 2010 and the Director of the 5G Innovation Centre since 2012. He has over 25 years of experience in digital communications research and teaching. He has authored and coauthored more than 800 research publications and is regularly invited to deliver keynote talks and distinguished lectures to international conferences and workshops. He has also edited two books: Technologies for the Wireless Future, Vol. 1 ( 2004) and Vol. 2 (2006) both published by Wileys. And he is co-inventor on more than 30 granted patents, all in the field of digital communications. Professor Tafazolli was the leader of study on grand challenges in IoT (Internet of Things) in the UK, 2011-2012, for RCUK (Research Council UK) and the UK TSB (Technology Strategy Board). In 2011, he was appointed as Fellow of the Wireless World Research Forum (WWRF) in recognition of his personal contributions to the wireless world as well as heading one of Europes leading research groups.

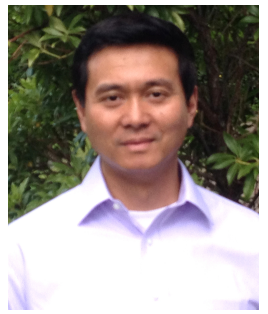

Pei Xiao (SM'11) received the B. Eng, MSc and $\mathrm{PhD}$ degree from Huazhong University of Science Technology, Tampere University of Technology, Chalmers University of Technology, respectively. Prior to joining the University of Surrey in 2011, he worked as a research fellow at Queens University Belfast and had held positions at Nokia Networks in Finland. He is a Reader at University of Surrey and also the technical manager of 5G Innovation Centre (5GIC), leading and coordinating research activities in all the work areas in 5GIC (http://www.surrey.ac.uk/5gic/research). Dr Xiaos research interests and expertise span a wide range of areas in communications theory and signal processing for wireless communications. 


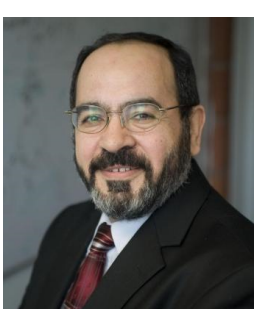

Ahmed Kishk (S'84-M'86-SM'90-F'98) received the B.S. degree in electronic and communication engineering from Cairo University, Cairo, Egypt, in 1977, the B.Sc. degree in applied mathematics from Ain-Shams University, Cairo, in 1980, and the M.Eng. and Ph.D. degrees from the Department of Electrical Engineering, University of Manitoba, Winnipeg, MB, Canada, in 1983 and 1986, respectively. He was a Distinguished Lecturer for the Antennas and Propagation Society from 2013 to 2015. Since 2011, he has been a Professor with Concordia University, Montreal, QC, Canada, as Tier 1 Canada Research Chair in Advanced Antenna Systems. He has authored over 300 refereed journal articles and 450 conference papers. He has co-authored four books and several book chapters and has edited three books. He offered several short courses in international conferences. His current research interests include millimeterwave antennas for $5 \mathrm{G}$ applications, analog beamforming network, dielectric resonator antennas, microstrip antennas, small antennas, microwave sensors, RFID antennas for readers and tags, multifunction antennas, microwave circuits, EBG, artificial magnetic conductors, soft and hard surfaces, phased array antennas, and computer aided design for antennas; reflect/transmitarray, wearable antennas, and feeds for parabolic reflectors. Dr. Kishk and his students were the recipients of several awards. He was the recipient of the 1995 and 2006 Outstanding Paper Award for papers published in the Applied Computational Electromagnetic Society Journal. He was an Editor of the IEEE Antennas and Propagation Magazine from 1993 to 2014. He was an Editorin-Chief of the ACES journal from 1998 to 2001. He was a member of the AP AdCom from 2013 to 2015. He is the 2017 AP President. 